\title{
Study on the Impact of Industrial Agglomeration on Ecological Sustainable Development in Southwest China
}

\author{
Lei Gao ${ }^{1}$, Fang $\mathrm{Li}^{2,3}{ }^{\text {, Jingran Zhang }}{ }^{1}$, Xu Wang ${ }^{1}$, Yue Hao ${ }^{4}$, Chao Li ${ }^{5}$, Yu Tian ${ }^{6}$, Chao Yang ${ }^{1}$, Weiming Song ${ }^{1, *}$ \\ and Tielong Wang $7, *$
}

1 School of Economics and Management, Beijing Forestry University, Beijing 100083, China; bertongao@bjfu.edu.cn (L.G.); zjrkdy@bjfu.edu.cn (J.Z.); wx712807@bjfu.edu.cn (X.W.); yangchao99@163.com (C.Y.)

2 School of Economics and Management, Beihang University, Beijing 100191, China; bjfu0726@163.com

3 China Centre for Promotion of SME Development, Beijing 100082, China

4 Business School, Beijing Normal University, Beijing 100875, China; 202031030026@mail.bnu.edu.cn

5 College of Mechanical and Electrical Engineering, Harbin Engineering University, Harbin 150001, China; 54529880@hrbeu.edu.cn

6 Institute of Ancient Books, Jilin University, Changchun 130012, China; yutian19@mails.jlu.edu.cn

7 Chinese Academy of Inspection and Quarantine, Beijing 100176, China

* Correspondence: bjfu0725@163.com (W.S.); wangtl@caiq.org.cn (T.W.)

Citation: Gao, L.; Li, F.; Zhang, J.; Wang, X.; Hao, Y.; Li, C.; Tian, Y.;

Yang, C.; Song, W.; Wang, T. Study on the Impact of Industrial

Agglomeration on Ecological Sustainable Development in Southwest China. Sustainability 2021,

13, 1301. https://doi.org/

10.3390/su13031301

Academic Editor: Ioannis Nikolaou

Received: 4 December 2020

Accepted: 19 January 2021

Published: 27 January 2021

Publisher's Note: MDPI stays neutral with regard to jurisdictional claims in published maps and institutional affiliations.

Copyright: (c) 2021 by the authors. Licensee MDPI, Basel, Switzerland. This article is an open access article distributed under the terms and conditions of the Creative Commons Attribution (CC BY) license (https:// creativecommons.org/licenses/by/ $4.0 /)$.

\begin{abstract}
Southwest China is a fragile terrestrial ecosystem restricted by its geological background, which leads to a contradiction between its industrial economic development and the ecological environment. In this study, to explore the influence and mechanisms of the three industrial agglomeration modes, namely, specialization, related diversification, and unrelated diversification, on the eco-efficiency of the region, linear and nonlinear regression models were applied to the data of five Southwest provinces from 2006 to 2018. Specialization agglomeration had a significant negative impact on the eco-efficiency of four provinces outside Tibet in Southwest China. With the decrease of industrial specialization, their eco-efficiency improved. The effects of related diversification agglomeration on the ecological efficiency of four provinces outside Tibet in Southwest China showed a " $U$ " curve. The degree of industrial diversification in these provinces exceeded the critical value of 1.46 , and the effect on eco-efficiency was shown. The unrelated diversification agglomeration had a negative effect on the ecological efficiency of the four provinces outside Tibet in Southwest China. The degree of industrial-unrelated diversification in Guizhou Province increased slightly, which was not conducive to the improvement of local eco-efficiency. Additionally, it decreased significantly in other provinces, which caused the improvement of local eco-efficiency. The conclusion provides a theoretical basis for industrial green transformation path selection and related policy formulation in Southwest China.
\end{abstract}

Keywords: sustainable development; industrial agglomeration; eco-efficiency; industrial transformation; Southwest China

\section{Introduction}

The Southwest China region covers five provinces, autonomous regions, and municipalities directly under the Central Government in Chongqing, Sichuan, Guizhou, Yunnan, and Tibet (Figure 1). The total area of the administrative divisions is 2.3406 million square kilometers, accounting for about $24.38 \%$ of the country's land area. At the end of 2019, the total population was 203 million, accounting for about $14.46 \%$ of the country's total population. Southwest China is a unique geographical unit with a large elevation slope, complex terrain patterns, and a complex ecological environment [1]. It is in this region where China's-and indeed the world's-largest tropical/subtropical karst area is located, in the form of the world's highest plateau-the Qinghai-Tibet Plateau. The total number of protected wild vertebrate species in Southwest China is 2426, representing 38.12\% of 
the total number of wild vertebrate species in China as a whole. The total number of wild higher plant species in the region is 20,965, which represents nearly $70 \%$ of the total number of wild higher plant species in China [2]. Southwest China is a globally recognized fragile terrestrial ecosystem greatly restricted by its geological background [3]. At the same time, the Southwest region is rich in mineral resources-130 types of minerals have been found-and the non-ferrous metals found in this region represent about $40 \%$ of the national reserves. For example, in Sichuan, vanadium and titanium reserves represent $82 \%$ and 33\% of the world's total reserves, respectively; in Yunnan, there are 112 non-ferrous metals, among which, zinc and germanium are the most abundant in the country; and Guizhou has 64 mines, among which 30 minerals, such as mercury, coal, aluminum, and phosphorus, are found at some of the highest levels in the country. In addition to the above provinces, Chongqing and Tibet have also formed non-ferrous metal resource smelting and processing industries of considerable scales. Presently, the industrial economic development economy in Southwest China has a high dependence on mineral resources, and because of the low energy utilization efficiency of local enterprises, the contradiction between local economic development and the ecological environment is very prominent. Some of the main consequences of this include soil desertification and water pollution [4]. Therefore, from the perspective of industrial ecology, it is very important to promote economic transformation - especially industrial transformation-in Southwest China, in order to realize the sustainable development of the region.

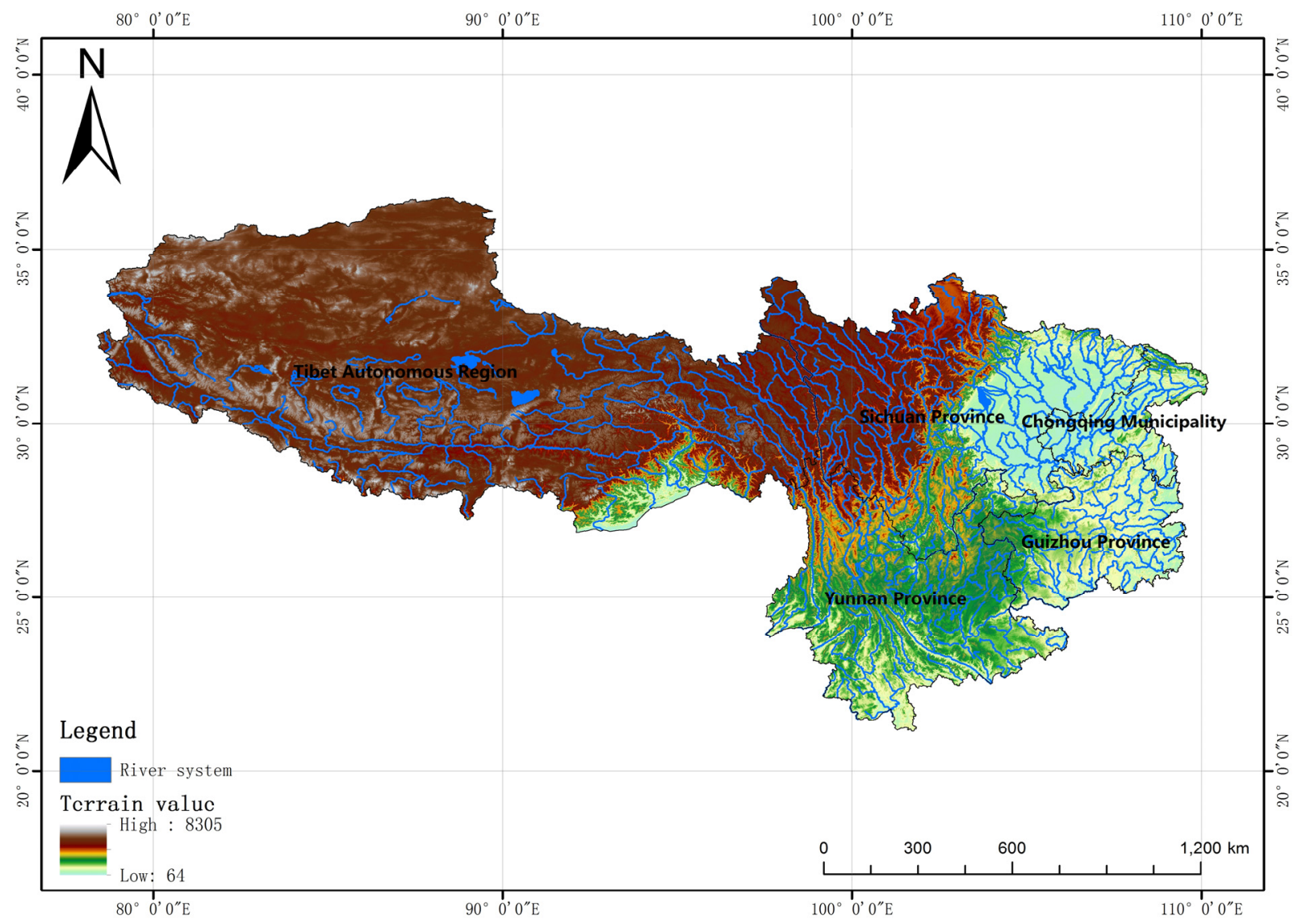

Figure 1. Southwest China (source: author's collation based on this article).

Industrial ecology has been at the center of a fierce conflict between economic development, environmental pollution, and resource shortages, and has been generally regarded as an important discipline by those aiming to achieve sustainable development. Industrial ecology is a new interdisciplinary subject that examines the relationship between human production activities and their dependent resources and the environment from the perspec- 
tive of resource bottleneck and environmental constraints. It mainly involves studying the relationship between enterprise behavior, the relationship between enterprises, and the relationship between enterprises and their dependent environment, with the purpose of understanding and optimizing these relationships in order to achieve the stability and sustainability of human production activities [5]. Currently, the research focus of industrial ecology mainly includes material metabolism, industrial symbiosis, life cycle evaluation, eco-efficiency, and industrial process optimization [6]. Eco-efficiency requires economic activities to consider economic benefits, resource utilization efficiency, and ecological and environmental benefits [7-9]. The existing research on eco-efficiency mainly focuses on its influencing factors [10,11], as well as its determination and evaluation in agriculture [12], ocean [13,14], industry [15], and urban ecological transformation [16,17]. In recent years, eco-efficiency determination has grown more diverse. For example, Dychkhoff used a preferred structure based on the traditional data envelopment analysis (DEA) model [18]. Sarkis used six DEA models to calculate and compare the eco-efficiency of power plants [19]. The slack-based model (SBM) and the directional distance function (DDF) were combined to form the SBM-DDF model, which was used to calculate industrial eco-efficiency [20]. This method not only solves the problem of the inaccurate calculation of input or output relaxation in the DDF model, but also eliminates the fault of the traditional DEA model by taking pollutant emissions as an input variable-a measure in accordance with reality [21].

Industrial agglomeration is generally regarded as an important way to achieve industrial transformation in resource-based areas [22,23]. According to their different forms, we can subdivide industrial agglomeration into specialization, related diversification, and unrelated diversification [24]. Specialization refers to the high convergence of enterprises in the same industry in a specific region [25]. Related diversification refers to the phenomenon by which different industry enterprises with a strong technology association level gather in specific regions. Unrelated diversification refers to the phenomenon by which different industry enterprises with weak technology association levels gather in specific regions [26]. Most scholars believe that there is an environmental Kuznets curve between industrial agglomeration and resource use [27-29]. Industrial agglomeration can improve the efficiency of resource utilization, production efficiency, and industrial levels through the mechanisms of technology spillover, input/output correlation, and facility sharing [30,31]. However, some people believe that industrial agglomeration can also produce negative externalities, such as pollution agglomeration and resource competition [32]. The external effects of different types of industrial agglomeration, such as specialization, related diversification, and unrelated diversification, are different $[33,34]$. Considering this, what are the different types of industrial agglomeration levels in Southwest China that are considered to be important ecological barriers? What is the ecological environment level in Southwest China? What is the effect of different types of industrial agglomeration on the ecological environment in Southwest China? In this paper, discussion of the above problems, based on the concept of sustainable development, will promote the comprehensive management of the ecological environment, as well as the green transformation and development of the regional economy in Southwest China.

This study will use linear and nonlinear regression models with industrial ecology, and economic and environmental statistics of Southwest China from 2006 to 2018 to explore an agglomeration path suitable for industrial transformation in Southwest China, and will provide the basis for formulating industrial green transformation policies in Southwest China. Lastly, the results of this study will provide ideas for choosing an industrial agglomeration path in other geological and ecological fragile areas.

\section{Materials and Methods}

\subsection{Source of Data}

Because of the limited availability of data and the consistency of the statistical caliber, the period chosen for this study was 2006-2018. The data in this paper were obtained from the China Statistical Yearbook [35], China Industrial Statistics Yearbook [36], China Environ- 
mental Statistics Yearbook [37], and five provinces (districts) in Southwest China [38-42]. The stock of industrial fixed assets was estimated using the perpetual inventory method, and the depreciation rate, based on Shan's [43] study, was set at 11.0. The industrial added value was converted into a comparable price based on the year 2000, which eliminated the influence of price change factors.

\subsection{Method for Measuring the Degree of Industrial Agglomeration}

\subsubsection{Measuring Methods for Specialization}

To measure the degree of industrial specialization, the Krugman specialization index [44] was calculated using the index of industrial industry sales output value. The formula is as follows:

$$
\text { spe }=\sum_{k=1}^{n}\left|F_{i k} / F_{i}-F_{k} / F\right|
$$

spe indicates the degree of specialization; in $F_{i k} / F_{i}, i$ indicates the share of the $k$ industry sales output value in the regional industrial sector; and $F_{k} / F$ indicates that the sales value of $k$ industries in the national industrial sector accounts for the share of the total industrial sales. The spe threshold is $(0,2)$; the greater the value, the higher the degree of specialization, and the lower the value, the lower the degree of specialization.

\subsubsection{Measuring Methods for Related and Unrelated Diversification}

Based on the input/output relationship and the technical distance between different industries, the entropy index method was used to measure the correlation diversification and independent diversification [26]. Next, referring to the Pan et al. [45] method, 35 doubledigit industries in the industrial sector were divided into four categories, and the entropy index of employees in large industries was used to express independent diversification. The weighted sum of the entropy index of the employees in subdivision industries indicated related diversification. The formula for this is as follows:

$$
\begin{gathered}
u r d=\sum_{k=1}^{N} E_{k} \ln \left(\frac{1}{V_{k}}\right) \\
V_{k}=\sum_{l=1}^{M_{k}} E_{l} \\
r d=\sum_{k=1}^{N} E_{k} H_{k} \\
H_{k}=\sum_{l=1}^{M_{k}} \frac{E_{l}}{E_{k}} \ln \left(\frac{1}{E_{l} / E_{k}}\right)
\end{gathered}
$$

$r d$ and urd indicate the degree of related diversification and unrelated diversification, respectively; $k$ indicates large industries according to the input/output relationship and technical distance; $l$ indicates the subdivision industries in large industries; $N$ indicates the number of subdivision industries in large industries; $M_{k}$ indicates $k$ number of subdivisions in large industries; and $E$ indicates the proportion of employees to the total number of industrial employees. The greater the value of the $r d$ threshold $(0,1.37)$, the stronger the degree of correlation diversification. The greater the value of the urd threshold $(0,2.69)$, the higher the degree of independent diversification.

\subsection{Measuring Methods for Industrial Eco-Efficiency}

\subsubsection{Global SBM-DDF Model}

This study combined the SBM and DDF models to form the SBM-DDF model, which was used to calculate the industrial eco-efficiency [20,21]. Suppose the $\mathrm{DMU}_{j}$ represents a decision unit with $J$ decision units, each DMU uses $M$ inputs $a=\left(a_{i}, a_{2}, \cdots, a_{m}\right) \in R_{M}^{+}$ 
to produce $\mathrm{N}$ expected output $b=\left(b_{1}, b_{2}, \cdots, b_{n}\right) \in R_{N}^{+}$and $\mathrm{Q}$ nonexpected output $c=\left(c_{1}, c_{2}, \cdots, c_{q}\right) \in R_{Q}^{+}$, then the product may be set as follows:

$$
P^{t}\left(a^{t}\right)=\left\{\left(b^{t}, c^{t}\right): \sum_{j=1, j \neq k}^{J} \lambda^{t} b_{j n}^{t} \geq b_{k n}^{t}, \forall_{n} ; \sum_{j=1, j \neq k}^{J} \lambda_{j}^{t} c_{j q}^{t} \leq c_{k q}^{t}, \forall_{q} ; \sum_{j=1, j \neq k}^{J} \lambda_{j}^{t} a_{j m}^{t} \leq a_{j m}^{t}, \forall_{m} ; \sum_{j=1, j \neq k}^{J} \lambda_{j}^{t}=1, \lambda_{j}^{t} \geq 0, \forall_{j}\right\}
$$

In Formula (6), $r$ represents the weight of the observed value of the decision unit-the ownership weight is non-negative and the sum is 1 , indicating that the scale reward is variable. In order to improve the intertemporal comparability of industrial eco-efficiency, this paper referred to the practice of Pastor et al. [46], and constructed the global production possibility set, $P^{G}=\left\{P^{1} \cup \cdots \cup P^{T}\right\}$, by using the production possibility set in the whole period. Considering the super efficiency, the following global SBM-DDF model is presented [47]:

$$
\begin{aligned}
& \overline{S_{V}^{t}}\left(a^{i, j}, b^{i, j}, c^{i, j}, h^{a}, h^{b}, h^{c}\right)=\frac{1}{2} \max \left[\frac{1}{N} \sum_{m=1}^{M} \frac{s_{m}^{a}}{h_{m}^{h}}+\frac{1}{N+K}\left(\sum_{n=1}^{N} \frac{s_{n}^{b}}{h_{n}^{b}}+\sum_{k=1}^{K} \frac{s_{q}^{c}}{h_{q}^{c}}\right)\right] \\
& \text { s.t. } \sum_{j=1, j \neq k}^{J} \lambda_{j}^{t} a_{j m}^{t}+s_{m}^{a} \leq x_{k m}^{t}, \forall_{m} \\
& \sum_{j=1, j \neq k}^{J} \lambda_{j}^{t} b_{j n}^{t}-s_{n}^{b} \geq a_{k n}^{t}, \forall_{n} \\
& \sum_{j=1, j \neq k}^{J} \lambda_{j}^{t} c_{j q}^{t}+s_{q}^{c} \leq c_{k q}^{t}, \forall_{q} \\
& \sum_{j=1, j \neq k}^{J} \lambda_{j}^{t}=1 \\
& s_{m}^{a} \geq 0, \forall_{m} ; s_{n}^{b} \geq 0, \forall_{n} ; s_{q}^{c} \geq 0, \forall_{q} ; \lambda_{j}^{t} \geq 0, \forall_{j}
\end{aligned}
$$

In Formula (7), $x, a$, and $b$ represent the input, expected output, and non-expected output, respectively; $\lambda$ represents the parameters to be evaluated; $\left(a^{i, j}, b^{i, j}, c^{i, j}\right)$ represent the input and output vectors for the $j$ DMU of the period; $\left(h^{x}, h^{a}, h^{b}\right)$ means that the input and output expansion values are positive direction vectors; and $\left(s_{n}^{a}, s_{m}^{b}, s_{q}^{c}\right)$ represents the input and output relaxation vectors.

\subsubsection{Selection of Indicators}

\begin{tabular}{|c|c|c|c|}
\hline & Variable Type & Variable Name & Variable Explanation \\
\hline \multirow{5}{*}{$\begin{array}{l}\text { Input } \\
\text { indicator }\end{array}$} & \multirow{3}{*}{ Natural resource input } & Water consumption & Total industrial water \\
\hline & & Land consumption & Area of industrial construction land \\
\hline & & Energy consumption & Total industrial energy consumption \\
\hline & Social and economic & Labor input & Number of industrial employees \\
\hline & factor input & Capital input & Industrial fixed assets \\
\hline \multirow{5}{*}{$\begin{array}{l}\text { Output } \\
\text { indicator }\end{array}$} & Desirable output & Economic value creation & Industrial value added \\
\hline & \multirow{4}{*}{ Undesirable output } & Wastewater discharge & $\begin{array}{l}\text { COD emissions industrial wastewater } \\
\text { Ammonium nitrogen emissions from industrial wastewater }\end{array}$ \\
\hline & & & $\mathrm{SO}_{2}$ emissions from industrial emissions \\
\hline & & gas disct & Smoke (dust) emissions from industrial waste gas \\
\hline & & Solid waste discharge & Emissions from industrial solid waste \\
\hline
\end{tabular}

From the perspective of input/output, this study selected the consumption of natural resources, such as water, land, and energy; the consumption of social and economic factors, such as labor and capital; and the economic value created by industrial activities as the expected output, and pollutant emissions from industrial activities as the nonexpected output (Table 1).

Table 1. Quantitative measurement variables of industrial eco-efficiency. 


\subsection{Panel Tobit Regression Model}

\subsubsection{Model Determination}

The industrial eco-efficiency calculated based on the global SBM-DDF model was greater than 0, so the Stata15.0 software was used to analyze the impact of industrial agglomeration on the eco-efficiency Tobit regression model [24]. The likelihood ratio (LR) test results showed that the $p$-value was significant, so the random effect panel Tobit model was used to analyze the eco-efficiency of industrial agglomeration and resource-based areas in Southwest China.

Because existing research has not yet reached an agreement on the influence of industrial agglomeration on eco-efficiency, the linear and nonlinear propositions between them were investigated individually. The regression model is as follows:

$$
y_{i t}=\alpha+\beta_{i t}+\gamma x_{i t}+\varepsilon_{i t}
$$

$y_{i t}$ is the explained variable, which indicates the industrial eco-efficiency of the $t$ period of $i$ provinces; $\beta_{i t}$ is the function form of the explanatory variable; $\alpha$ and $\varepsilon_{i t}$ are the intercept terms and random disturbance terms, respectively; $x_{i t}$ is a control variable. In this study, $\beta_{i t}$ can be $(\lambda s p e),\left(\lambda s p e+\theta s p e^{2}\right),\left(\lambda r d+\theta r d^{2}\right),(\lambda u r d)$, or $\left(\lambda u r d+\theta u r d^{2}\right)$, resulting in six regression models, indicated as models $1-6$.

\subsubsection{Selection of Control Variables}

According to the existing literature, in addition to the situation of industrial agglomeration, the factors that affect eco-efficiency include the level of regional development, energy structure, the degree of opening to the outside world, technological progress, the intensity of environmental regulation, and the degree of marketization [48,49]. The ratio of per capita GDP (pgdp) coal consumption to total energy consumption (estur), Chinese and foreign investment in industrial enterprises (open), R \& D funds, and industrial added value of industrial enterprises above the previous period (tech); the ratio of completed investment in industrial pollution control to industrial added value (envir); and the ratio of main business income of non-state-owned enterprises to the main business income of enterprises above scale (mark) were all measured and included in the regression model in the form of control variables.

\section{Results and Discussion}

\subsection{Industrial Agglomeration in Southwest China in 2006-2018}

Based on Formulas (1)-(5), the three types of industrial agglomeration in Southwest China were measured. The concrete results are shown in Table 2.

Table 2. Industrial agglomeration in Southwest China in 2006-2018.

\begin{tabular}{|c|c|c|c|c|c|c|c|c|c|c|c|c|c|c|}
\hline Type & Region & 2006 & 2007 & 2008 & 2009 & 2010 & 2011 & 2012 & 2013 & 2014 & 2015 & 2016 & 2017 & 2018 \\
\hline \multirow{7}{*}{ Specialization } & Chongqing & 0.83 & 0.82 & 0.82 & 0.81 & 0.80 & 0.82 & 0.81 & 0.77 & 0.79 & 0.80 & 0.80 & 0.81 & 0.81 \\
\hline & Sichuan & 0.82 & 0.83 & 0.83 & 0.85 & 0.86 & 0.82 & 0.80 & 0.79 & 0.78 & 0.78 & 0.79 & 0.79 & 0.78 \\
\hline & Guizhou & 0.89 & 0.89 & 0.86 & 0.87 & 0.88 & 0.90 & 0.89 & 0.86 & 0.83 & 0.72 & 0.75 & 0.77 & 0.80 \\
\hline & Yunnan & 0.97 & 0.98 & 0.92 & 0.91 & 0.89 & 0.88 & 0.86 & 0.85 & 0.84 & 0.84 & 0.85 & 0.86 & 0.86 \\
\hline & Tibet & 0.04 & 0.03 & 0.03 & 0.03 & 0.03 & 0.04 & 0.03 & 0.03 & 0.03 & 0.03 & 0.03 & 0.03 & 0.03 \\
\hline & Mean & 0.71 & 0.71 & 0.69 & 0.69 & 0.69 & 0.69 & 0.68 & 0.66 & 0.65 & 0.63 & 0.64 & 0.65 & 0.66 \\
\hline & Chongqing & 1.58 & 1.58 & 1.60 & 1.61 & 1.61 & 1.58 & 1.58 & 1.57 & 1.59 & 161 & 1.63 & 1.63 & 1.64 \\
\hline \multirow{5}{*}{$\begin{array}{c}\text { Related } \\
\text { diversification }\end{array}$} & Sichuan & 1.55 & 1.56 & 1.59 & 1.61 & 1.62 & 1.62 & 1.62 & 1.63 & 1.63 & 1.64 & 1.64 & 1.65 & 1.66 \\
\hline & Guizhou & 1.55 & 1.46 & 1.40 & 1.37 & 1.31 & 1.34 & 1.34 & 1.36 & 1.41 & 1.55 & 1.54 & 1.55 & 1.57 \\
\hline & Yunnan & 1.63 & 1.63 & 1.61 & 1.61 & 1.60 & 1.61 & 1.61 & 1.65 & 1.69 & 1.71 & 1.70 & 1.71 & 1.71 \\
\hline & Tibet & 0.00 & 0.00 & 0.00 & 0.00 & 0.00 & 0.00 & 0.00 & 0.00 & 0.00 & 0.00 & 0.00 & 0.00 & 0.00 \\
\hline & Mean & 1.26 & 1.25 & 1.24 & 1.24 & 1.23 & 1.23 & 1.23 & 1.24 & 1.26 & 1.30 & 1.30 & 1.31 & 1.32 \\
\hline \multirow{6}{*}{$\begin{array}{l}\text { Unrelated } \\
\text { diversification }\end{array}$} & Chongqing & 1.25 & 1.26 & 1.25 & 1.25 & 1.25 & 1.24 & 1.24 & 1.25 & 1.26 & 1.26 & 1.25 & 1.24 & 1.21 \\
\hline & Sichuan & 1.29 & 1.27 & 1.24 & 1.22 & 1.20 & 1.20 & 1.19 & 1.17 & 1.18 & 1.20 & 1.21 & 1.21 & 1.22 \\
\hline & Guizhou & 1.21 & 1.23 & 1.24 & 1.24 & 1.25 & 1.25 & 1.26 & 1.26 & 1.27 & 1.28 & 1.28 & 1.29 & 1.31 \\
\hline & Yunnan & 1.32 & 1.29 & 1.30 & 1.30 & 1.29 & 1.30 & 1.30 & 1.30 & 1.31 & 1.30 & 1.29 & 1.29 & 1.28 \\
\hline & Tibet & 0.00 & 0.00 & 0.00 & 0.00 & 0.00 & 0.00 & 0.00 & 0.00 & 0.00 & 0.00 & 0.00 & 0.00 & 0.00 \\
\hline & Mean & 1.01 & 1.01 & 1.01 & 1.00 & 1.00 & 1.00 & 1.00 & 1.00 & 1.00 & 1.01 & 1.01 & 1.01 & 1.00 \\
\hline
\end{tabular}

Note: because of the low employment numbers in Tibet's industrial industry, the final measurement result is less than 0.005 . Therefore, the data on Tibet are recorded as 0.00 (source: author's collation based on this article.) 
From the point of view of the entire Southwest China region, there are obvious differences in the time trends of different types of industrial agglomerations from 2006 to 2018. The degree of industrial specialization in Southwest China generally showed a downward trend, with the average of the five provinces falling from 0.71 to 0.65 (Table 2). The degree of industrial specialization in Chongqing and Tibet changed slightly. The reason for this phenomenon may be that the proportion of local industrial output value in the GDP was too high or too low. Chongqing's share of industrial output in GDP remained at $45-50 \%$ for many years, whereas Tibet's figure remained at $5-7.5 \%$ for many years. Other provinces showed a downward trend year by year, with Yunnan and Guizhou declining significantly by 0.11 and 0.09 , respectively. The degree of industrial-related diversification agglomeration in Southwest China showed a trend of decreasing first and then increasing. The average for the five provinces declined from 1.26 in 2006 to 1.23 in 2011, and then gradually rebounded to 1.38 in 2018 . With the exception of Tibet, other provinces generally showed a fluctuating upward trend, but the increase was less than 0.06 . The biggest increase was in Sichuan, where the measure of industrial-related diversification agglomeration rose 0.11. From 2006 to 2018, the changes in the degree of industrial independent diversification in Southwest China were not significant, with the average of the five provinces fluctuating around 1.00. Guizhou's industrial independent diversification slightly decreased, with a decline of 0.07. In addition to Tibet, Chongqing, Sichuan, and Yunnan showed an upward trend, with increases of $0.02,0.10$, and 0.02 , respectively.

\subsection{Level of Industrial Eco-Efficiency in Southwest China in 2006-2018}

Based on Formulas (6) and (7), the industrial eco-efficiency of Southwest China was measured, and the results are shown in Table 3.

Table 3. Industrial eco-efficiency of resource-based areas from 2006-2018.

\begin{tabular}{|c|c|c|c|c|c|c|c|c|c|c|c|c|c|}
\hline Region & 2006 & 2007 & 2008 & 2009 & 2010 & 2011 & 2012 & 2013 & 2014 & 2015 & 2016 & 2017 & 2018 \\
\hline Chongqing & 1.09 & 1.11 & 1.11 & 1.13 & 1.14 & 1.19 & 1.21 & 1.21 & 1.22 & 1.24 & 1.24 & 1.26 & 1.27 \\
\hline Sichuan & 1.01 & 1.03 & 1.03 & 1.04 & 1.05 & 1.05 & 1.05 & 1.07 & 1.08 & 1.12 & 1.11 & 1.12 & 1.13 \\
\hline Guizhou & 0.97 & 1.01 & 0.96 & 0.89 & 0.83 & 0.75 & 0.73 & 0.71 & 0.66 & 0.72 & 0.72 & 0.75 & 0.75 \\
\hline Yunnan & 1.04 & 1.11 & 1.03 & 1.17 & 1.06 & 1.18 & 1.19 & 1.16 & 1.20 & 1.19 & 1.18 & 1.20 & 1.21 \\
\hline Tibet & 0.32 & 0.35 & 0.35 & 0.36 & 0.37 & 0.37 & 0.37 & 0.38 & 0.39 & 0.40 & 0.41 & 0.41 & 0.40 \\
\hline Mean value & 0.89 & 0.92 & 0.90 & 0.92 & 0.89 & 0.91 & 0.91 & 0.91 & 0.91 & 0.93 & 0.93 & 0.95 & 0.95 \\
\hline
\end{tabular}

(Source: author's collation based on this article).

From 2006 to 2018, the industrial eco-efficiency in Southwest China was in a fluctuating state (Table 3). The industrial eco-efficiency of Guizhou decreased year by year, and that of the other provinces increased. Among them, Chongqing and Yunnan's growth rates were relatively large -0.18 and 0.17 , respectively. Qinghai's growth rate was relatively small—only 0.08 .

\subsection{Influence of Industrial Agglomeration on Eco-Efficiency in Southwest China}

Based on Formula (8), the relationship between industrial specialization agglomeration, industrial-related diversification agglomeration, industrial-unrelated diversification agglomeration, and eco-efficiency in Southwest China was measured empirically. The results are shown in Table 4. 
Table 4. Regression results of the impact of industrial agglomeration on eco-efficiency in Southwest China.

\begin{tabular}{|c|c|c|c|c|c|c|}
\hline Explanatory Variable & Model 1 & Model 2 & Model 3 & Model 4 & Model 5 & Model 6 \\
\hline spe & $\begin{array}{c}-0.433^{* * *} \\
(-2.85)\end{array}$ & $\begin{array}{c}-1.862 \text { ** } \\
(-2.25)\end{array}$ & & & & \\
\hline$s p e^{2}$ & & $\begin{array}{l}0.813 \\
(1.56)\end{array}$ & & & & \\
\hline$r d$ & & & $\begin{array}{l}-0.147 \\
(-1.13)\end{array}$ & $\begin{array}{c}-4.376^{* * *} \\
(-2.97)\end{array}$ & & \\
\hline$r d^{2}$ & & & & $\begin{array}{c}1.451 \text { *** } \\
(2.65)\end{array}$ & & \\
\hline urd & & & & & $\begin{array}{l}-0.436 * \\
(-1.95)\end{array}$ & $\begin{array}{l}-0.287 \\
(-0.07)\end{array}$ \\
\hline$u r d^{2}$ & & & & & & $\begin{array}{l}-0.061 \\
(-0.06)\end{array}$ \\
\hline$p g d p$ & $\begin{array}{c}-0.174^{* * *} \\
(-3.75)\end{array}$ & $\begin{array}{c}-0.162 * * * \\
(-3.49)\end{array}$ & $\begin{array}{c}-0.117^{* * *} \\
(-2.74)\end{array}$ & $\begin{array}{c}-0.146^{* * *} \\
(-3.45)\end{array}$ & $\begin{array}{l}-0.088 \text { * } \\
(-1.98)\end{array}$ & $\begin{array}{l}-0.087 * \\
(-1.79)\end{array}$ \\
\hline$p g d p^{2}$ & $\begin{array}{c}0.036^{* * *} \\
(4.65)\end{array}$ & $\begin{array}{c}0.034^{* * *} \\
(4.39)\end{array}$ & $\begin{array}{c}0.029 * * * \\
(3.84)\end{array}$ & $\begin{array}{c}0.033^{* * *} \\
(4.47)\end{array}$ & $\begin{array}{c}0.025^{* * *} \\
(3.27)\end{array}$ & $\begin{array}{c}0.025^{* * *} \\
(3.21)\end{array}$ \\
\hline estur & $\begin{array}{c}-0.944^{* * *} \\
(-5.51)\end{array}$ & $\begin{array}{c}-0.999 * * * \\
(-5.76)\end{array}$ & $\begin{array}{c}-0.963^{* * * *} \\
(-5.57)\end{array}$ & $\begin{array}{c}-0.936^{* * *} \\
(-5.89)\end{array}$ & $\begin{array}{c}-0.934^{* * *} \\
(-5.65)\end{array}$ & $\begin{array}{c}-0.935^{* * *} \\
(-5.51)\end{array}$ \\
\hline open & $\begin{array}{l}-0.162 \\
(-0.22)\end{array}$ & $\begin{array}{l}-0.196 \\
(-0.25)\end{array}$ & $\begin{array}{l}0.047 \\
(0.06)\end{array}$ & $\begin{array}{l}0.026 \\
(0.04)\end{array}$ & $\begin{array}{l}0.279 \\
(0.38)\end{array}$ & $\begin{array}{l}0.279 \\
(0.38)\end{array}$ \\
\hline tech & $\begin{array}{l}6.78 * * \\
(2.17)\end{array}$ & $\begin{array}{c}7.609 * * \\
(2.44)\end{array}$ & $\begin{array}{c}6.975^{* *} \\
(2.14)\end{array}$ & $\begin{array}{c}5.073 * \\
(1.75)\end{array}$ & $\begin{array}{c}6.781 \text { ** } \\
(2.10)\end{array}$ & $\begin{array}{c}6.804^{* *} \\
(2.05)\end{array}$ \\
\hline envir & $\begin{array}{l}2.825 \\
(0.89)\end{array}$ & $\begin{array}{c}3.25 \\
(1.07)\end{array}$ & $\begin{array}{l}4.180 \\
(1.27)\end{array}$ & $\begin{array}{l}2.662 \\
(0.82)\end{array}$ & $\begin{array}{c}6.967^{* *} \\
(1.98)\end{array}$ & $\begin{array}{c}6.954^{* *} \\
(1.96)\end{array}$ \\
\hline mark & $\begin{array}{c}0.019 * \\
(1.68)\end{array}$ & $\begin{array}{l}0.008 \\
(0.58)\end{array}$ & $\begin{array}{c}0.022 \text { * } \\
(1.85)\end{array}$ & $\begin{array}{c}0.018 \text { * } \\
(1.67)\end{array}$ & $\begin{array}{l}0.014 \\
(1.01)\end{array}$ & $\begin{array}{l}0.014 \\
(1.01)\end{array}$ \\
\hline Constant & $\begin{array}{c}1.762 * * * \\
(8.28)\end{array}$ & $\begin{array}{c}2.413^{* * *} \\
(5.39)\end{array}$ & $\begin{array}{c}1.454^{* * *} \\
(6.27)\end{array}$ & $\begin{array}{c}4.546^{* * *} \\
(4.01)\end{array}$ & $\begin{array}{c}1.776^{* * *} \\
(5.98)\end{array}$ & $\begin{array}{l}1.677 \\
(0.53)\end{array}$ \\
\hline Observations & 50 & 50 & 50 & 50 & 50 & 50 \\
\hline Number of ID & 5 & 5 & 5 & 5 & 5 & 5 \\
\hline
\end{tabular}

Note: ${ }^{*} p<0.1 ;{ }^{* *} p<0.05 ;{ }^{* * *} p<0.01$. spe-specialization; $r d$-related diversification; urd-unrelated diversification; $p g d p$-regional development level; estur — energy structure; open — the opening degree to the outside world; tech — technical progress; envir-environmental regulation intensity; mark — degree of marketization (source: author's collation based on this article).

It can be seen from Table 4 that specialization agglomeration has a significant negative effect on industrial eco-efficiency in Southwest China. From 2006 to 2018, besides Tibet, the other province had a decline in industrial specialization, which led to an improvement in eco-efficiency. However, because of the proportion of the industrial output value, the measurement results of industrial specialization in Tibet fluctuated slightly at 0.04 . This is because the specialized agglomeration of the mineral mining and processing industry is usually manifested in the collection of resource enterprises in the region, the contribution rate of technological progress is low, and the efficiency of resource development and utilization is limited [49]. It is strongly related to capital, labor force, and other factors, which leads to a poor mobility of production factors and a low efficiency of resource allocation, and thus, a low production efficiency [50].

As can be seen from Table 4, the influence of related diversification agglomeration on industrial eco-efficiency in Southwest China has a " $U$ " curve characteristic; the critical value is 1.46. By the end of 2018, the degree of industrial-related diversification in provinces other than Tibet had exceeded the critical value, and the eco-efficiency of these provinces had also improved with the degree of industrial-related diversification. This is because when the degree of related diversification does not exceed the critical value, the circular economy effect and the scale effect of pollution control caused by industrial diversification agglomeration have not yet occurred. At this time, the resource consumption, energy consumption, and environmental performance of most mineral enterprises are not good, the negative impact on resources and the environment is greater, the economic added value is low, and the economic benefit is poor. The division of labor and cooperation among 
enterprises is mainly based on product production needs, the low level of technological innovation, and the lack of significant improvement in the level of resource development and utilization and in production technology. When the degree of relevant diversification exceeds the critical value, cross-border cooperation and communication between enterprises tend to be frequent, and knowledge spillover promotes the development and utilization of resources technology and production efficiency. More importantly, relevant diversification agglomeration is conducive to the formation of industrial symbiosis. On the one hand, product transactions between different enterprises may be completed in the agglomeration area, effectively reducing not only material loss and waste in the transportation process, but also the time cost and transportation cost of the transaction. On the other hand, the byproduct or waste of one enterprise may become the raw material or intermediate input of another enterprise, benefiting the recycling of resources and of waste, improving the efficiency of resource utilization, and reducing the discharge of pollutants and wastes [14].

It can be seen from Table 4 that unrelated diversification agglomeration has a significant negative effect on industrial eco-efficiency in Southwest China. From 2006 to 2018, the degree of industrial-unrelated diversification in Guizhou increased slightly, which led to a decline in eco-efficiency. The degree of industrial-unrelated diversification in the other provinces decreased significantly, resulting in an improvement in eco-efficiency. The reason for this may be that when enterprises with a long technology distance and low input/output correlation degree gather, it is hard to improve the efficiency of resource utilization and production because of the difficulty of knowledge spillover and technological innovation. More importantly, resource-based unrelated diversification often means that emerging industries outside resource-based industries are concentrated within the region. However, for a long time, the dependence of traditional resource-based industries on factors of production in Southwest China has led to a lack of high-quality talents, finances, environments, and other elements in these areas. Because of the low matching degree between the supply of factors of production in this area and the demand for advanced factors of production in emerging industries, it is difficult to form a symbiosis between traditional and modern industries. This leads to difficulties in the multi-level recycling of resources.

Among most models, there is a " $\mathrm{U}$ " curve relationship between the regional development level and industrial eco-efficiency in Southwest China. The reason for this is that when the level of regional development is low, people pay more attention to economic benefits; the mode of production is extensive; and the problems of waste of resources, environmental pollution, and ecological destruction are serious. When the level of regional development is high, the ecological environment and social economy become the focus of attention, and eco-efficiency begins to improve. Coal-based energy structures are not conducive to the improvement of industrial eco-efficiency, because coal consumption often brings $\mathrm{SO}_{2}$ (sulfur dioxide), dust, smoke, and other pollution. The effect of foreign investment on industrial eco-efficiency is limited, and this is related to the application and diffusion of advanced production technology and management experience of foreign-funded enterprises in local areas. Technological progress has effectively improved industrial eco-efficiency, and pollution control has had a limited effect on eco-efficiency. Reducing the proportion of state-owned enterprises is beneficial to improving industrial eco-efficiency, because the market economy facilitates the free flow of factors of production and the optimal allocation of resources.

\section{Conclusions}

To truly understand the influence and mechanism of the three industrial agglomeration modes-specialization, related diversification, and independent diversification-on ecoefficiency in the Southwest China region, this study applied linear and nonlinear models to data from five provinces in Southwest China from 2006 to 2018. Because of the relative particularity of Tibet's industrial structure and ecological environment, this study will 
divide the conclusions into two parts-one for Tibet and the other for the other four provinces of Southwest China, excluding Tibet. The conclusions are as follows.

\subsection{Effects of Different Types of Industrial Agglomeration on Ecological Efficiency in Four} Southwest Chinese Provinces, Besides Tibet

Industrial specialization agglomeration has a significant negative impact on the ecoefficiency of four provinces in Southwest China, other than Tibet. Therefore, industrial specialization agglomeration is not conducive to industrial green transformation in these areas. This research showed that because of the pressure of national and local environmental regulations, the degree of industrial specialization agglomeration in the four provinces decreased, which led to an improvement in local ecological efficiency. The above results can be explained by the fact that the industrial specialization agglomeration in the Southwest region is usually manifested in the resource-based industry agglomeration of nonferrous metal mining or smelting, and these enterprises have a large energy consumption, backward clean production technology, and a strong dependence on the origin of minerals, making it easy to cause environmental pollution and ecological damage.

The effects of industrial-related diversification agglomeration on the eco-efficiency of the four provinces in Southwest China, excluding Tibet, have " $U$ " curve characteristics. Based on the analysis of the measurement results, the current industrial-related diversification agglomeration is a relatively effective path to take for industrial green transformation in these areas. During the research period, the degree of industrial-related diversification agglomeration in the four provinces exceeded the critical value, and the degree of industrial-related diversification agglomeration in Chongqing, Sichuan, and Yunnan (not Guizhou) improved, which made the eco-efficiency of the three provinces significantly better than that of Guizhou. This is because the current industrial-related diversification agglomeration in these four provinces has produced a circular economy effect and a scale effect of joint pollution control. Cross-border exchanges and cooperation between enterprises tend to be frequent with the increasing degree of related diversification agglomeration, which promotes the improvement of resource utilization technology, production efficiency, and energy efficiency.

Industrial-unrelated diversification agglomeration has a negative impact on the ecoefficiency of the four provinces in Southwest China, excluding Tibet. Therefore, industrialunrelated diversification agglomeration is not conducive to industrial green transformation in these areas. During the research period, the degree of industrial-related diversification agglomeration in Chongqing, Sichuan, and Yunnan (excluding Guizhou) decreased, which made the ecological efficiency of these three provinces significantly better than that of Guizhou. This is due to the difficulty of knowledge spillover, resource utilization efficiency, and production efficiency. Resource sharing is difficult to realize, causing production and operation costs to rise. The dependence of resource-based industries on factors of production and the exclusion of other industries lead to a poor matching degree of supply and demand of advanced factors of production, and to difficulty when recycling energy. Compared with the other three neighboring provinces, Guizhou has a larger proportion of nonferrous metal mining and processing industries in the local national economy.

\subsection{Effects of Different Types of Industrial Agglomeration on Ecological Efficiency in Tibet}

Tibet is a key ecological functional and demonstration area for biological protection in China. It is located in the Qinghai-Tibet Plateau. Under the influence of landform, altitude, and other factors, Tibet has formed unique ecological conditions, and its wildlife resources are very rich. Furthermore, because of the alpine and arid climate in Tibet, the population density is low, the industrial structure is relatively unique, and the level of economic development is low. In particular, the proportion of the industrial output value to the overall output value of the whole country is at a lower level in the whole country.

Because of the low value of various industrial data in Tibet, the measurement results of various types of industrial agglomeration in Tibet in this study are not obvious. By observing the empirical results, we find that the measurement results of industrial specialization 
in Tibet remained at 0.04 or less. The degree of industrial diversification agglomeration and the degree of nonrelated diversification in Tibet were less than 0.005, which is not significant. However, it is certain that the degree of diversification in Tibet is below the critical value. Tibet's ecological efficiency also rose slightly from 0.89 in 2008 to 0.95 in 2018. "The promulgation and implementation of China's Tibet Ecological Security Barrier Protection and Construction Plan (2008-2030)" has played an important role in improving Tibet's ecological efficiency.

However, we should also keep in mind that the task of urbanization, industrialization, and agricultural modernization in Tibet is arduous, and the pressure of ecological environment protection is enormous. With the continuous development of the social economy in Tibet, the contradiction between development and protection will become more and more prominent.

The optimization of the industrial structure in Southwest China should fully acknowledge to the role of environmental regulation in promoting the industrial structure, as well as realize the win-win situation between environmental protection and industrial structure upgrading. Although the mineral resource reserves in Southwest China are among the highest in the country, their clean processing of mineral resources is relatively backward compared with that in developed countries and regions. Therefore, we should encourage the Southwest region to build an open economy and improve the efficiency of energy conservation and carbon emission reduction. On the one hand, we must actively encourage local enterprises to obtain advanced environmental protection technology from abroad; strengthen international exchanges and cooperation; adhere to green and low-carbon orientation; and promote openness, tolerance, and complementary advantages among countries. On the other hand, enterprises should strengthen economic exchanges with other regions in China, promote the dynamic balance of various elements with positive economic activities, and reduce the pressure on local resources and environment. Local governments can also promote energy conservation and carbon emission reduction by using appropriate policy incentives, such as improving the relevant price and financial support policies for energy conservation and the carbon emission reduction of outstanding industrial enterprises that implement the relevant preferential policies. The government needs to implement relevant rewards and punishments or control policies to promote energy conservation and carbon emission reduction, strengthen the implementation of government laws and regulations, and increase awareness of local governments about their environmental responsibility. The government should increase the inspection and supervision of energy conservation and carbon emission reduction processes, implement punitive prices or blacklisting for enterprises with high pollution emissions, and suspend the projects of such enterprises. The whole society needs to set up ecological ethics guidelines to make environmental protection behaviors become passive and active, to actively organize and carry out energy saving and carbon emission reduction education activities, to encourage and guide society to carry out green consumption and production, to actively create a good atmosphere for energy conservation and emission reduction, and to build an economic-development-friendly and environmentally-friendly society.

Author Contributions: Conceptualization, L.G., F.L., T.W. and W.S.; data curation, L.G., T.W., Y.H. and C.Y.; formal analysis, C.L., Y.T. and J.Z.; project administration, W.S. and C.Y.; visualization, J.Z. and X.W.; writing - original draft, L.G. and J.Z.; writing-review and editing, X.W. All authors have read and agreed to the published version of the manuscript.

Funding: This study was funded by the National Natural Science Foundation Youth Project (grant number 72003013), the Major Research Achievement Cultivation Project of Beijing Forestry University (grant number pyxm001), and the Key R \& D projects of Hebei Province Study on the browning control method in the thermal process of flexible pouch chestnut; (grant number 20327113D).

Institutional Review Board Statement: Not applicable.

Informed Consent Statement: Not applicable. 
Acknowledgments: We acknowledge the work of past and present advisors and technical, research, and data management staff in supporting the data collection and providing the laboratory analyses for this project.

Conflicts of Interest: The authors declare no conflict of interest.

\section{References}

1. Gao, X.; Cao, H. Evaluation of Industrial Development and Policies in Southwest Chinaern China in the Past 70 Years from the Perspective of Low-carbon Economy. J. Lanzhou Univ. Soc. Sci. 2019, 47, 11-23.

2. Cheng, G.; Chen, X.; Lan, Q. An Analysis of Coupling Degree between Economic Development and Ecological Environment in Southwest China along the Silk Road Economic Belt: An Empirical Test Based on DEA Entropy-Weight TOPSIS Model. Int. Bus. 2018, 96-106.

3. Feng, X.; Dong, M. On Influence of Resources and Environment upon Economic Development in Southwest China. J. Southwest China Minzu Univ. (Philos. Soc. Sci.) 2018, 67-72.

4. Graedel, T.E.; Allenby, B.R.; Hall, P. Industrial Ecology. Indus. Ecol. 2002, 12, 18-26.

5. Yuan, Z.; Bi, J. Industrial Ecology; Science Press: Beijing, China, 2010; pp. 21-23.

6. Wang, X.; Shi, X. A review of industrial ecology based on GIS. Acta Ecol. Sin. 2017, 37, 1346-1357.

7. Cagle, A.E.; Armstrong, A.; Exley, G.; Grodsky, S.M.; Macknick, J.; Sherwin, J.; Hernandez, R.R. The Land Sparing, Water Surface Use Efficiency, and Water Surface Transformation of Floating Photovoltaic Solar Energy Installations. Sustainability 2020, $12,8154$. [CrossRef]

8. Shen, W.; Hu, Q.; Li, J.; Chen, Q. Spatio-temporal evolution and spatial interaction of regional eco-efficiency in China. J. Nat. Resour. 2020, 35, 2149-2162.

9. Dong, J.; Wu, D. An Evaluation of the Impact of Ecological Compensation on the Cross-Section Efficiency Using SFA and DEA: A Case Sturdy of Xin' an River Basin. Sustainability 2020, 12, 7966. [CrossRef]

10. Xing, Z.; Wang, J.; Zhang, J. Research on regional totalfactor eco-efficiency of China: Measurement and determinants. China Popul. Resour. Environ. 2018, 28, 119-126.

11. Yang, Y.; Deng, X. The spatio-temporal evolutionary characteristics and regional differences in affecting factors analysis of China's urban eco-efficiency. Sci. Geogr. Sin. 2019, 39, 1111-1118.

12. Hou, M.; Yao, S. Convergence and differentiation characteristics on agro-eco-efficiency in China from a spatial perspective. China Popul. Resour. Environ. 2019, 29, 116-126.

13. Di, Q.; Liang, Q. Spatio-temporal difference of marine eco-efficiency and identification of its response relationship with marine industrial structure in China. Sci. Geogr. Sin. 2018, 38, 1606-1615.

14. Gai, M.; Zhan, Y. Spatial evolution of marine eco-efficiency and its influential factors in China coastal regions. Sci. Geogr. Sin. 2019, 39, 616-625.

15. Miao, Z.; Miao, Z. Progress in Chinese and International Industrial Ecological Engineering Development. Ecol. Econ. 2012, 8, 112-117.

16. Yin, K.; Wang, R.; Zhou, C.; Liang, J. Review of eco-efficiency accounting method and its applications. Acta Ecol. Sin. 2012, 32, 3595-3605. [CrossRef]

17. Zhou, G.; Peng, H.; Cao, F. Circular Economy and Industrial Eco-efficiency Indicator System. Urban Environ. Urban Ecol. 2003, 16, 201-203.

18. Dyckhoff, H.; Allen, K. Measuring eco-efficiency with data envelopment analysis (DEA). Eur. J. Oper. Res. 2001, 132, 312-325. [CrossRef]

19. Sarkis, J. Ecoefficiency: How data envelopment analysis can be used by managers and researchers. In Environmentally Conscious Manufacturing; International Society for Optics and Photonics: Bellingham, WA, USA, 2001; Volume 4193, pp. $194-203$.

20. Fukuyama, H.; Weber, W.L. A directional slacks-based measure of technical inefficiency. Socio Econ. Plan. Sci. 2010, 43, $274-287$. [CrossRef]

21. Chen, S. Evaluation of low carbon transformation process for Chinese provinces. Econ. Res. J. 2012, 47, 32-44.

22. Chen, W.; Huang, X.; Liu, Y.; Luan, X.; Song, Y. The Impact of High-Tech Industry Agglomeration on Green Economy EfficiencyEvidence from the Yangtze River Economic Belt. Sustainability 2019, 11, 5189. [CrossRef]

23. Liu, Z.; Huang, Q.; He, C.; Wang, C.; Wang, Y.; Li, K. Water-energy nexus within urban agglomeration: An assessment framework combining the multiregional input-output model, virtual water, and embodied energy. Resour. Conserv. Recycl. 2021, 164, 105113. [CrossRef]

24. Wang, Y.; Miao, C.; Hu, Z.; Zhang, Y. Specialization, diversity and their impacts on China's provincial industrial pollution emissions. J. Nat. Resour. 2019, 34, 586-599.

25. Marshall, A. Principles of Economics; MacMillan: London, UK, 1890; pp. 12-13.

26. Frenken, K.; Oort, F.V.; Verburg, T. Related Variety, Unrelated Variety and Regional Economic Growth. Reg. Stud. 2007, 41, 685-697. [CrossRef]

27. Ma, J.; Qin, T.; Tong, J.; Sun, D. Industrial agglomeration, urban agglomeration, and water consumption. Soft Sci. 2018, 32, 95-99.

28. Dong, F.; Wang, Y.; Zheng, L.; Li, J.; Xie, S. Can industrial agglomeration promote pollution agglomeration? Evidence from China. J. Clean. Prod. 2019, 246, 118960. [CrossRef] 
29. Wag, X.; Yu, C. Impact of spatial agglomeration on industrial pollution emissions intensity in China. China Environ. Sci. 2017, $37,1562-1570$

30. Ke, S.; Yao, D. The causal relationship and determinants of industrial agglomeration and urban labor productivity. J. Quant. Tech. Econ. 2008, 25, 3-14.

31. Shi, B.; Shen, K. The government intervention, the economic agglomeration, and the energy efficiency. Manag. World 2013, 6-18.

32. Yang, C. An Analysis on the Spatio-Temporal Difference and Convergence of China's Industrial Eco-efficiency. Macroeconomics 2020, 106-113.

33. Lei, Y.; Zheng, M.; Sun, J. The Impact of Industrial Agglomeration on Haze Pollution of Key Urban Agglomerations in China. Soft Sci. 2020, 34, 64-69.

34. Zhang, G.; Chen, C. Research on Dynamic Relationship between Industrial Agglomeration and Urban eco-efficiency. Sci. Technol. Prog. Policy 2019, 36, 48-57.

35. National Bureau of Statistics of China. China Statistical Yearbook; Statistics Press: Beijing, China, 2016-2018.

36. Department of Industry Statistics, National Bureau of Statistics of China. China Industry Statistical Yearbook; Statistics Press: Beijing, China, 2006-2018.

37. National Bureau of Statistics; Ministry of Environmental Protection of China. China Statistical Yearbook on Environment; Statistics Press: Beijing, China, 2006-2018.

38. Statistics Bureau of Chongqing; NBS Sarvey Office in Chongqing. Chongqing Statistical Yearbook; Statistics Press: Beijing, China, 2006-2018.

39. Statistics Bureau of Sichuan; NBS Sarvey Office in Sichuan. Sichuan Statistical Yearbook; Statistics Press: Beijing, China, 2006-2018.

40. Statistics Bureau of Yunnan; NBS Sarvey Office in Yunnan. Yunnan Statistical Yearbook; Statistics Press: Beijing, China, $2006-2018$.

41. Statistics Bureau of Guizhou; NBS Sarvey Office in Guizhou. Guizhou Statistical Yearbook; Statistics Press: Beijing, China, 2006-2018.

42. Statistics Bureau of Tibet Autonomous Region; NBS Sarvey Office in Tibet Autonomous Region. Tibet Statistical Yearbook; Statistics Press: Beijing, China, 2006-2018.

43. Shan, H. Re-estimating the capital stock of China: 1952-2006. J. Quant. Tech. Econ. 2008, 25, 17-31.

44. Wei, H. Modern Regional Economics; Economic \& Management Press: Beijing, China, 2011; pp. $163-171$.

45. Pan, W.; Li, Z.; Liu, Q. Inter-industry technology spillover effects in China: Evidence from 35 industry sectors. Econ. Res. J. 2011, 46, 18-29. [CrossRef]

46. Pastor, J.T.; Lovell, C.A.K. A global Malmquist productivity index. Econ. Lett. 2005, 88, 266-271. [CrossRef]

47. Cheng, G. Data Envelopment Analysis: Methods and MaxDEA Software; Intellectual Property Press: Beijing, China, $2014 ;$ pp. $200-201$.

48. Li, C.; Zhang, S.; Zhang, W. Spatial distribution characteristics and influencing factors of China's interprovincial industrial eco-efficiency. Sci. Geogr. Sin. 2018, 38, 1970-1978.

49. Feng, J.; Zang, Q. Study on the coordination and influencing factors of eco-efficiency and scientific and technological innovation of industrial enterprises. J. Tech. Econ. 2020, 39, 35-42.

50. Shao, S.; Fan, M.; Yang, L. How does resource industry dependence affect economic development efficiency. Manag. World 2013, 2, 32-63. 